\title{
An investigation into the effect of a resin infiltrant on the micromechanical properties of hypomineralised enamel.
}

\section{HARLEEN KUMAR ${ }^{1,2}$, JOSEPH E A PALAMARA ${ }^{1}$, MICHAEL $F$ BURROW $^{1}$, DAVID J MANTON ${ }^{1}$}

${ }^{1}$ Oral Health Cooperative Research Centre, Melbourne Dental School, The University of Melbourne, Melbourne, Australia.

${ }^{2}$ Boston Children's Hospital and Harvard School of Dental Medicine, Boston, Massachusetts, USA.

Correspondence to:

D. J. Manton, Paediatric Dentistry, Melbourne Dental School, The University of Melbourne, Victoria, Australia, 3010. E-mail: djmanton@unimelb.edu.au

Acknowledgement:

The authors would like to thank Dr. Felicity Crombie for her assistance with conceptualising the methods in this study.

Author contributions: J.E.A.P., H.K. and D.J.M. conceived the ideas; H.K. collected the data; H.K. analysed the data; H.K., D.J.M., J.E.A.P., and M.F.B. led the writing

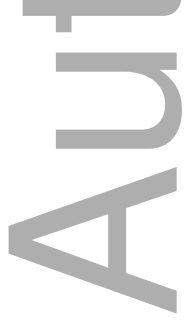

This is the author manuscript accepted for publication and has undergone full peer review but has not been through the copyediting, typesetting, pagination and proofreading process, which may lead to differences between this version and the Version of Record. Please cite this article as doi: 10.1111/ipd.12272

This article is protected by copyright. All rights reserved 
Received Date : 04-Jul-2016

Revised Date : 07-Sep-2016

Accepted Date : 12-Sep-2016

Article type : Original Article

\section{MAIN DOCUMENT}

Title

An investigation into the effect of a resin infiltrant on the micromechanical properties of hypomineralised enamel.

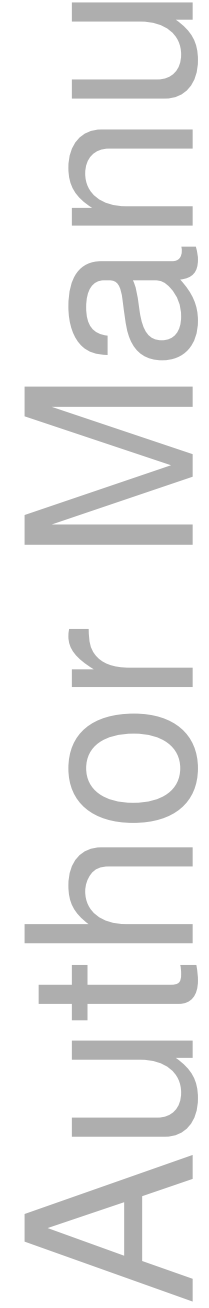

\section{Summary}

This article is protected by copyright. All rights reserved 
Background. Resin infiltration may alter the mechanical properties of enamel hypomineralised lesions (HL), however, variable surface layer (SL) thickness may affect resin penetration.

Aims. To determine the thickness of the SL of HL and to investigate the effect of resin infiltration on the mechanical properties of HL.

Design. The thickness of the SL over HL was determined using polarised light microscopy. Etching time using $15 \% \mathrm{HCl}$ gel to remove the SL of 52 samples was determined. Selected HL and control areas of 21 teeth were infiltrated with Icon ${ }^{\circledR}$ resin infiltrant and cross-sectional Knoop micro-hardness (KHN) measurements were recorded before and after resin infiltration.

Results. Ninety-six point five percent of HL had a detectable SL with mean thickness of $58 \pm 29 \mu \mathrm{m}$. Application of $\mathrm{HCl}$ for $120 \mathrm{~s}$ produced a mean MIH erosion depth of $58 \pm 12 \mu \mathrm{m}$. Eleven of 21 samples had evidence of infiltration using visual examination. The infiltrant penetrated some of the HL leading to an increase in KHN $(111 \pm 75 \mathrm{KHN})$ which, when compared to adjacent non-infiltrated HL (96 \pm 52 $\mathrm{KHN})$, was not statistically significantly different $(\mathrm{p}=0.56)$.

Conclusions. There was marked variation in the SL thickness of HL. Resin infiltration of HL did not increase microhardness significantly.

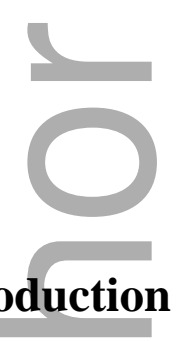

\section{Introduction}

The clinical management of enamel hypomineralisation lesions (HL) found in teeth affected by molar incisor hypomineralisation (MIH) can present several challenges to both the patient and clinician. Treatment of first permanent molars (FPM) in particular can be problematic. MIH involves one or more FPM and often other teeth such as the permanent incisors and primary molars. These lesions are soft and porous and can undergo post-eruptive enamel breakdown (PEB), develop extensive carious lesions, and have the predisposition for marginal breakdown of restorations leading to frequent re-treatment ${ }^{1,2}$. 
At present, there are no reports of restorative techniques of hypomineralised teeth with good prognosis. The problem lies not with the restorative material itself but with the compromised ultrastructure of the enamel, subsequent impaired acid-etching pattern as well as the interface between the material and the $\mathrm{HL}^{2,3}$. Improving the mechanical properties of the HL could be critical to successful restorative care, or preventing PEB in the first place.

The concept of resin infiltration involves occluding the inter-rod spaces of white spot lesions of enamel with low viscosity resins to limit ionic diffusion and arrest or slow the progress of the lesion ${ }^{4}$. This has the potential to be applied to HL. Successful penetration of resin infiltrant into MIH affected enamel may improve its micromechanical properties. It is postulated that infiltration of HL with a low viscosity light curing resin may increase hardness of the lesion, reduce porosity and permeability, prevent or reduce $\mathrm{PEB}$, and therefore negate the need for restorative intervention or lead to a less destructive restoration. Resin infiltration of HL may improve bond strength of a restoration at the infiltrant surface and thereby minimise the risk of marginal breakdown. If resin infiltration of HL allows for reduced enamel porosity, aids in creating an adequate seal, and improves its micromechanical properties, the process may diminish sensitivity to oral stimuli.

Similar to the relatively hypermineralised surface layer (SL) overlying the more porous lesion body of non-cavitated carious lesions, HL can also have a visually sound $\mathrm{SL}^{5-7}$. In carious lesions, the SL acts as a barrier that can hamper the penetration of infiltrant significantly ${ }^{4}$. Removal of the SL is required to gain access to the more porous lesion body for successful infiltration. Removing the SL of HL partly or entirely, to increase surface porosity, may allow greater accessibility of the infiltrant to the underlying hypomineralised enamel.

Knowledge of SL characteristics over MIH affected lesions is limited. The present study aimed to determine the thickness of the SL over MIH affected lesions and the amount of erosion produced by etching HL for various times. A second aim was to measure the cross-sectional hardness of MIH affected FPM and investigate the effect of resin infiltration on the micromechanical properties of hypomineralised enamel. 


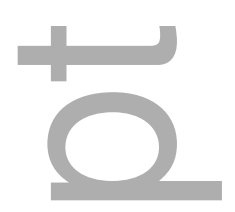

Material and Methods

\section{Specimen collection, storage and classification}

Informed consent was obtained and ethics approval granted by the Human Research Ethics Committee of the University of Melbourne and the Dental Health Services Victoria Human Research Ethics Committee Ethics ID 0932749. Dental clinicians collected a pooled convenience sample of 225 extracted, erupted FPM from children under the age of 18 years diagnosed clinically to be affected with MIH. Three sound FPM from patients that did not have MIH were also collected after extraction for orthodontic reasons. Collected teeth were extracted due to dental caries, extensive PEB or for orthodontic purposes. Sound teeth were defined as those teeth without visible signs of developmentally or pathologically affected enamel. Participating practitioners stored extracted teeth in clear aqueous chlorhexidine $(0.02 \% \mathrm{w} / \mathrm{v}$; Baxter Pty Ltd, Toongabbie, NSW, Australia). Within seven days of extraction, the investigators confirmed using judgement criteria provided by Weerheijm et al. for the diagnosis of $\mathrm{MIH}^{1}$. Specimens were transferred to $1 \%$ Chloramine-T hydrate (SigmaAldrich Co., St. Louis, USA) with a $\mathrm{pH}$ of 9.1 for $14 \mathrm{~d}$ at room temperature, then stored in sealed containers at room temperature and $100 \%$ humidity until use.

Areas of 'normal'/ sound enamel on MIH affected teeth adjacent to a HL were classified following visual inspection as being free of carious lesions, PEB, hypoplasia, demarcated opacities and diffuse opacities. Only teeth with distinct areas of at least $2 \mathrm{~mm}$ diameter of control and hypomineralised enamel were included in the study in order to allow an adequate surface area for sectioning and testing. A modified version of the 10-point scoring system created by Ghanim et al. based on the European Academy of Paediatric Dentistry evaluation criteria was used to categorize teeth $^{1,8}$. Wet specimens were categorised into mild, moderate and severe by scoring 
the most severely affected area according to colour, presence or absence of PEB, and extent of the HL (Table 1).

\section{Etch time and surface layer analysis}

Eleven MIH teeth with mild or moderate HL were selected which after sectioning of the lesions provided 52 samples from the teeth for etch time analysis (Fig. 1). Group 1 included the HL from each tooth, and Group 2 included visually sound control enamel from the same tooth. Exposure times with $\mathrm{HCl}$ (hydrochloric acid gel) $(15 \% \mathrm{HCl}$, Icon $^{\circledR}$, DMG, Hamburg, Germany) of 90 s, 120 s, and 240 s (120 x 2 s) were selected to determine which was the ideal etch time for a HL. Lesion types were allocated evenly to each etch time group. The same HL samples were used for surface layer analysis except for the addition of 5 samples in the mildly affected enamel (90 s) subgroup bringing the total to 57 samples.

The roots of selected FPM were sectioned and acid resistant nail varnish (Revlon red 680, Revlon Inc., NY, USA) was applied to the areas surrounding the selected regions (Fig. 2a-c). Each HL and its adjacent control enamel had $\mathrm{HCl}$ gel applied with a microbrush with a randomly allocated etching time, rinsed with water for $30 \mathrm{~s}$ and dried with oil-free compressed air from a triplex syringe. The $240 \mathrm{~s}$ etch group involved a $120 \mathrm{~s}$ etch, rinsing with water for $30 \mathrm{~s}$, repeating the etching procedure for a further $120 \mathrm{~s}$ followed by rinsing and drying.

The etched specimens were embedded in clear cold curing polymethyl methacrylate (PMMA) resin (Paladur, Heraeus Kulzer, Hanau, Germany) and sectioned into 0.7 - $1 \mathrm{~mm}$ sections with a slow-speed water-cooled peripheral diamond-bladed saw (Minitom; Struers, Ballerup, Denmark) (Fig. 2d, e). The sections were lapped wet (RotoPol, Struers, Ballerup, Denmark) to a thickness of $100 \mu \mathrm{m}$ using a series of silicon carbide lapping papers (1200, 2500 and 1200/4000 grit). Sections were examined using polarised light microscopy (PLM) (Leica DML, Wetzlar, Germany) under water imbibition (enamel $\leq 5 \%$ porosity, refractive index 1.33). Images of the sections were taken at $5 \mathrm{X}$ and $20 \mathrm{X}$ magnification with a camera (DFC 320; Leica, Wetzlar, Germany) linked to the PLM and a computer. The images were accessed using the corresponding microscope software (IM50 Image Manager; 
Leica, Wetzlar, Germany) and analysed by measuring the erosive depths in enamel and the surface layer thickness using ImageTool software (UTHSCSA ImageTool v. 3.00 for Microsoft Windows). Surface layers were measured only on the mesial, distal, buccal or lingual surface of the molars where the HL was present. Descriptive analysis was performed of the resulting values and outcomes using SPSS Version 20.0 (IBM Corp., NY, USA).

\section{Resin infiltration}

Sample size was calculated using the results of a pilot study by Crombie et al. ${ }^{4}$. Based on a power of $80 \%$ with an alpha level of 0.05 , an estimated sample size of 11 teeth would be required to demonstrate an improvement in microhardness after resin infiltration by a factor of 1.6 and a common standard deviation of 0.5 . MIH-affected specimens were allocated into two groups; Group 1 (Test; $n=21)$ and Group 2 (Control; $n=23$ ). A third group of non-MIH affected enamel $(n=3)$ from sound teeth was also included to validate the hardness measurements and allow comparison of normal enamel to the other groups (Fig. 3). Groups 1 and 2 were subdivided into mild HL and moderate HL. In preparation for infiltration and hardness testing, the HL was sectioned perpendicular to the enamel surface through the centre of the lesion giving paired test and control halves (Fig. 4 a-b).

The cut surfaces of both halves were covered with an acid-resistant nail varnish that formed a barrier during the infiltration procedure and prevented exposure of the cut surfaces to the test agents (Fig. 4c). The test half of each specimen comprised of the HL (HL test group) as well as the visually sound enamel apical to the lesion (sound test group). Test halves were exposed to $15 \% \mathrm{HCl}$ for $120 \mathrm{~s}$ then underwent the infiltration process as per the manufacturer's guidelines (Icon ${ }^{\circledR}, \mathrm{DMG}$, Hamburg, Germany).

The test and control specimens were embedded in PMMA resin, sectioned and polished as described above until the varnish on the cut surface was removed to expose the area to be assessed for hardness testing (Fig. 4d, e). All samples were subjected to hardness testing to determine the effects of resin infiltration (Wilson Hardness $^{\mathrm{TM}}$, MA, USA). 
Samples were placed on the stage of a light microscope (Leica, Wetzlar, Germany) with a microhardness testing device and kept hydrated throughout. Knoop hardness indentations were made on the enamel surface $(\mathrm{F}=25 \mathrm{~g}, \mathrm{~T}=10 \mathrm{~s})$ spaced at $100-150 \mu \mathrm{m}$ intervals within hypomineralised enamel and $200-300 \mu \mathrm{m}$ intervals within control enamel. Images of indentations were captured using a $50 \mathrm{X}$ lens objective and the diagonal length of each indentation was measured in $\mu \mathrm{m}$ and input into the integrated calculator to produce a Knoop Hardness (KHN) number which equals the load $(\mathrm{kg}) /$ area of indent $\left(\mathrm{mm}^{2}\right)$. The area to be tested on the samples was divided into zones to allow data to be recorded according to location within a sample (Fig. 5). The cross-sectional indentation line profile for the samples consisted of a series of indentations within enamel from the occlusal cusp tip to the cervical region.

Infiltration of test samples was determined visually under $5 \mathrm{X}$ magnification where changes in the colour, shape or opacity of the HL or sound test enamel were recorded and compared with the control half to check for its absence. Descriptive and statistical analysis was performed of the resulting KHN values and outcomes.

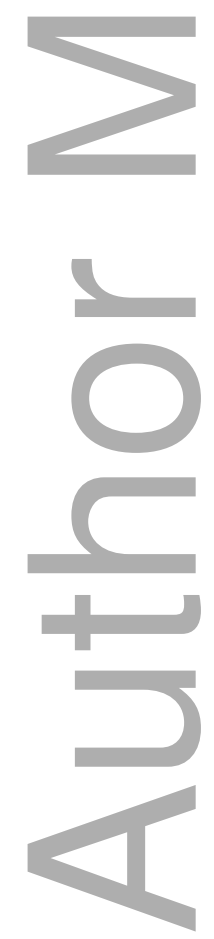




\section{Results}

\section{Etch time}

Comparison of the mean enamel erosion depth for the different etch times found an increasing trend in the amount of enamel lost as the etching times increased from 90 to $240 \mathrm{~s}$ (Fig. 6 a-c). This was the same for both the mild and moderately affected enamel groups. Mild and moderately affected HL exposed to $\mathrm{HCl}$ for $90 \mathrm{~s}, 120 \mathrm{~s}$ and $240 \mathrm{~s}$ analysed collectively produced a mean enamel erosion depth of $44.3 \pm 14.2 \mu \mathrm{m}$, $58.3 \pm 12.4 \mu \mathrm{m}$ and $104.6 \pm 15.8 \mu \mathrm{m}$ respectively. Similarly, in the sound test group, the mean enamel erosion loss after etching for $90 \mathrm{~s}, 120 \mathrm{~s}$ and $120 \mathrm{~s}$ repeated twice was $36.1 \pm 8.7 \mu \mathrm{m}, 56.9 \pm 12.4 \mu \mathrm{m}$ and $88.8 \pm 13.8 \mu \mathrm{m}$ respectively. When the results of both mild and moderate groups were combined, it was found that for all etch times, the sound test group had comparatively less enamel loss than the HL test group.

Specimens with moderately affected HL eroded more than their mildly affected counterparts in the $120 \mathrm{~s}$ HL group. Mild MIH HL eroded more than moderate HL in the $90 \mathrm{~s} \mathrm{HL}$ and $120 \times 2$ HL groups.

\section{Surface layer analysis}

Analysis of the specimens using PLM under water imbibition allowed visualisation of the SL. Of the 57 samples with HL, 52 had a visible SL, three were excluded because the HL was sub-surface with significant control enamel overlying it, and two samples did not have a SL present over the test site surface of the specimen. The mean SL thickness was $57.8 \mu \mathrm{m}$ (Table 2). The mean SL thicknesses for mildly and moderately affected MIH samples were $52.7 \mu \mathrm{m}$ and $62.9 \mu \mathrm{m}$ respectively.

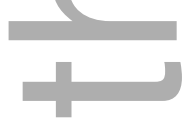

For 12 of 21 of the samples $(57.1 \%)$ an etch time of $90 \mathrm{~s}$ did not erode the entire SL overlying the HL. Six of 15 samples (40.0\%) with SL visible under PLM etched for $120 \mathrm{~s}$ did not have erosion of the entire SL. Fourteen of 16 samples (87.5\%) exposed to $\mathrm{HCl}$ for $240 \mathrm{~s}$ had complete erosion of the SL in addition to underlying hypomineralised enamel from two to more than six times the thickness of the SL. This extensive loss of enamel was visible clinically. 
Specimens for the SL study were prepared so multiple samples could be obtained for analysis from a single specimen when possible. This allowed observation of variation within a HL as slices were typically taken $0.7-1 \mathrm{~mm}$ apart. Great variation was noted in the size, shape and location of HL within the same specimen (Fig. 7).

Surface layer thickness differed for all samples taken from the same specimen. The greatest variation was found in Specimen 3 where the difference in SL thicknesses between the samples was up to $100.9 \mu \mathrm{m}$ (Table 3).

\section{Resin infiltration}

\section{Hardness analysis of non-MIH samples and control samples}

Cross-sectional Knoop indentations were made on the cut surfaces from the occlusal cusp tip to the cervical region of three non-MIH affected FPM to measure KHN values of normal enamel. The mean KHN value of non-MIH affected molars was $295.87 \pm 27.39 \mathrm{KHN}$. A paired samples t-test revealed there was no statistically significant difference between cervical enamel of control samples (303.25 \pm 9.73 $\mathrm{KHN})$ and cervical enamel of non-MIH affected molars $(\mathrm{p}=0.65)$.

The mean KHN of hypomineralised areas of mild versus moderately affected control samples was calculated. Due to wide variability, a non-parametric test (Mann Whitney U-test) was used. Mean KHN of mildly affected enamel $(97.33 \pm 54.2)$ was greater than moderately affected enamel $(81.24 \pm 61.72)(\mathrm{p}=0.33)$.

Plotting the KHN values for control samples revealed a trend in changes in hardness according to location. Knoop hardness was within normal levels at the cusp tip in samples with visually sound enamel above the HL (Fig. 8). Further into hypomineralised enamel, KHN declined then increased again closer to the cervical margins of the lesion. Hardness values within normal limits were recorded in cervical enamel below the HL. Samples with hypomineralised enamel extending to the cusp tip without occlusal visually sound enamel present had lower KHN readings than nonMIH affected enamel (Fig. 9) 
Six consecutive KHN readings of the most severely affected region (lowest KHN values) in HL of mild and moderate control samples were compared (Table 4). Hardness values as low as $1.6 \mathrm{KHN}$ were recorded in a moderately affected sample compared with sound enamel which had readings around 300 KHN. Repeated measures of ANOVA of the most severely affected regions in hypomineralised enamel of control samples found a statistically significant difference between mild and moderately affected enamel $(\mathrm{p}=0.02)$.

\section{Visual and hardness analysis of infiltrated test samples}

Twenty-one test samples (10 with mildly affected and 11 with moderately affected hypomineralised enamel) were infiltrated. Under visual examination of the 21 samples, 11 had areas within the HL, which appeared to be infiltrated (Fig 10). Eight of these infiltrated samples had moderately affected enamel and three had mildly affected enamel.

Despite application of the infiltrant over the entire smooth surface of the sample, it was noted that the infiltrant penetrated only a small proportion of the HL. The pattern of infiltration was not uniform and did not infiltrate within the same region for all samples. The depth of infiltration within HL reached 500-750 $\mu \mathrm{m}$ in some samples.

A comparison was made of all hardness readings taken from the occlusal cusp to cervical region of test samples divided into those that appeared to have been infiltrated under visual examination and those that did not. The comparison revealed an increase in hardness trend within the infiltrated HL of approximately $15 \%$ (p = 0.56) (Fig. 11).

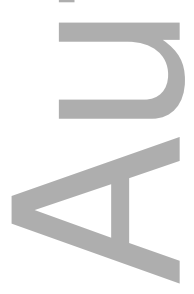

\section{Discussion}

This article is protected by copyright. All rights reserved 
With increasing etching times the erosion depth increased, and hypomineralised enamel eroded more than visually sound enamel from a tooth with MIH. This may be attributed to the increased porosity of hypomineralised enamel allowing greater penetration of $\mathrm{HCl}$ and its mineral content being more soluble ${ }^{5,9,10}$.

By inference, since hypomineralised enamel eroded more than visually sound control enamel, one would expect more severely hypomineralised enamel to have greater erosion. This, however, was not the case and mildly affected enamel was eroded more than its moderately affected counterpart in the $90 \mathrm{~s}$ and $240 \mathrm{~s}$ groups. The cause for this finding cannot be explained and may be due to the great variation in mineral content between affected teeth. Further information on the samples such as the surface layer thickness of each sample, mineral density, age at which they were extracted, exposure to remineralising agents and a larger sample size in the study may aid in gaining further understanding of the effects of $\mathrm{HCl}$ erosion on $\mathrm{MIH}$ teeth.

In the present study, under PLM with water imbibition, the SL had a negative birefringence similar to that of the normally mineralised control enamel. The presence of a protective outer enamel layer may explain why the smooth surfaces of the samples had not undergone PEB before extraction.

The mean SL thickness was $57.8 \mu \mathrm{m}$ ranging from 18.5 - $145.4 \mu \mathrm{m}$. Given $120 \mathrm{~s}$ etch-time eroded the same amount of enamel as the mean SL thickness, $120 \mathrm{~s}$ was selected as the application time prior to exposing the samples to resin infiltrant. Similar to the present findings of a wide range in surface layer thickness, Suckling et al. described two white demarcated opacities located on the same tooth; one with a SL approximately $25 \mu \mathrm{m}$ wide and the second with a translucent band approximately 300 $\mu \mathrm{m}$ wide ${ }^{11}$. Our findings substantiate the fact that SL thickness can be irregular and can vary significantly not only between teeth but within teeth and individual lesions.

The present study confirms previous findings that colour of a lesion can be a good indication of its mechanical properties ${ }^{11,5}$. When all KHN values within a mildly affected lesion were compared with those within a moderately affected lesion, a statistically significant difference between white vs. yellow/brown lesions was not found. This may be because the KHN values towards the outer extent (occlusal and 
cervical) of the lesion were high in both groups thereby averaging the KHN values. When only six consecutive readings within the lesion with lowest KHN values were compared, a statistically significant variation was noted. Whilst brown HL were assessed, the present study did not examine KHN values of severe HL with PEB.

Knoop hardness values as low as $1.6 \mathrm{KHN}$ were recorded in one moderately affected sample, a $99.5 \%$ decrease in hardness compared with sound enamel. A dramatic decrease in hardness may have clinical ramifications such as a greater susceptibility to PEB, caries, sensitivity and possibly be associated with a higher rate of marginal breakdown of restorations, however, the micromechanical properties of MIH affected teeth have not yet been correlated with clinical consequences.

Hardness values within normal levels at the cusp tip in samples with visually sound enamel above the HL were determined. This has not been reported previously. Previous Ultra-Micro-Indentation hardness studies of MIH affected teeth identified a linear decrease in hardness from the cervical to the hypomineralised enamel occlusally $^{12-14}$. This may be because the samples were not separated from those with sound enamel occlusal to the HL and those with hypomineralisation extending to the cusp tip. The present study found lower hardness values located occlusally compared to sound enamel only in those samples with hypomineralisation extending to the cusp tip.

The KHN of enamel from the sound test group was not statistically significantly different to that of enamel from non-MIH affected samples, in accordance with findings from other studies ${ }^{12,14}$. Enamel in the cervical third of MIH affected teeth appears visually and under PLM to be normal ${ }^{15,16}$. The present study confirmed this, where all selected specimens prior to sectioning appeared visually to have sound enamel in the cervical third.

A 0.5 - $1 \mathrm{~mm}$ long transition zone between the hypomineralised and sound cervical enamel has been described with a linear reduction in hardness and mineral density from the cervical to the hypomineralised enamel occlusally ${ }^{13,17,18}$. The present study found the same transition zone is also present between sound enamel around the occlusal cusp tip and hypomineralised enamel positioned cervical to it. Hardness 
readings in the transition zone ranged between those of sound and hypomineralised enamel. Farah et al. proposed the more severely affected enamel may be due to ameloblasts being in the transition stage which are more susceptible to the effects of an insult vs. less susceptible ameloblasts located in the transition zone going through the late secretory or maturation stages ${ }^{17}$. The results from the present study suggest ameloblasts are affected only for a certain period of time where the occlusal transition zone may indicate the start of the insult and the cervical transition zone may display the end of the effect of the insult(s).

Twenty-one samples were exposed to Icon $^{\circledR}$, of which eight of eleven moderately affected and three of ten mildly affected MIH samples infiltrated visibly. The more severely affected enamel may be infiltrated more than mild enamel due to its greater porosity and reduced mineral density. This trait of resin infiltration is advantageous clinically where treatment of the more severely affected lesions may be possible as these are more prone to PEB and marginal breakdown of restorations.

The infiltrant penetrated only a small proportion of the HL not within the same region for all samples. It may be that the increased protein content in HL hampers resin penetration similar to carious lesions ${ }^{4}$. A study analysing protein content found a 3 - 15 fold higher protein content in MIH enamel than sound enamel ${ }^{19}$. If protein content was the only factor impeding resin infiltration, one would expect more mildly affected samples with presumably lower protein content to infiltrate to a greater extent than moderately affected samples, which was not the case in this experiment.

It is possible other factors may contribute to unsuccessful resin infiltration such as incomplete SL removal. An in vivo study assessing the effect of Icon $^{\circledR}$ resin infiltrant on white spot lesions of teeth with developmental defects of enamel and teeth with post-orthodontic demineralisation found $40 \%$ of teeth did not mask the clinical appearance of white spot lesions after resin infiltration ${ }^{20}$. This failure was attributed to the depth of the lesion which may be greater than the infiltration depth, and the lesion activity where older/inactive lesions may have had a thicker SL that was only partly removed with etching and thus allowed only incomplete penetration with resin infiltrant. 
In the present study, the depth of resin infiltration within HL did not reach the DEJ similar to the results of another recent study ${ }^{21}$. In samples that did display resin infiltration, $\mathrm{HCl}$ application may have allowed complete erosion of the SL as well as a part of the underlying hypomineralised enamel, or the SL was relatively narrow, thereby exposing the body of the lesion to resin infiltration allowing its deeper penetration into enamel. It is possible deeper $\mathrm{HCl}$ penetration may have allowed more enamel proteins to denature thereby creating a positive effect with regards to resin infiltration. Other components in Icon ${ }^{\circledR}$ may also contribute to resin penetration such as the ethanol in the dessicant Icon Dry ${ }^{\circledR}$ which can denature proteins, and the flow characteristics of the resin. Improving the protein degrading properties and the flow characteristics of the Icon $^{\circledR}$ system may aid in its improved penetration within hypomineralised enamel. Further research into this area is required.

There was a $15 \%$ increase in KHN for those teeth that had visible resin infiltration compared with those that did not from the test groups although this was not statistically significant. Resin infiltration of HL has been shown to have no significant effect on microshear bond strengths to resin composite, however, it is not known if infiltration would be associated with clinical benefits such as reduced sensitivity and $\mathrm{PEB}^{3}$.

Given the limited infiltration of hypomineralised enamel with an unreliable pattern in the present study, it can be argued that removal of the relatively sound SL present in the majority of teeth will further weaken the tooth structure by exposing more porous parts of the lesion, causing further reduction in adhesion of sealants and restorative materials on the surface, increase sensitivity and PEB. Hypomineralised enamel can have a relatively thick overlying SL, which may be the only natural protecting factor of the lesion. Another disadvantage of resin infiltration is that it is very likely to hamper subsequent remineralisation attempts. Occluding the pores of hypomineralised enamel with resin will block the diffusion of ions into and out of enamel thereby impeding significant remineralisation.

At present, resin infiltration of MIH affected teeth cannot be recommended as a clinical procedure. Further investigations into improving the reliability and 
penetration of resin infiltrant on $\mathrm{MIH}$ affected enamel are recommended. With improved understanding of the physical, micromechanical, and biochemical properties of hypomineralised enamel and with further research into resin infiltration, it may become a viable approach to treating MIH affected enamel in the future.

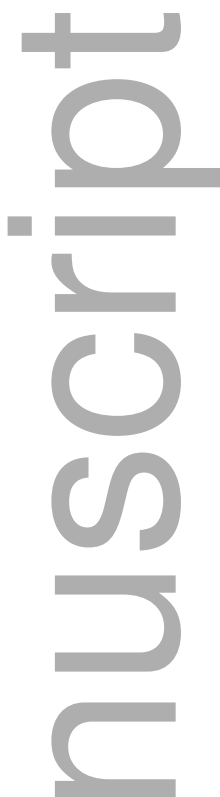

\section{Why the paper is important to paediatric dentists}

- Improved understanding of the characteristics of the SL overlying HL as well as erosion depth changes produced by etching HL for various times

- The microhardness properties of MIH affected teeth have been described

- This study found that resin infiltration of HL did not increase microhardness significantly. Potential benefits of resin infiltration of hypomineralised enamel have been discussed which may allow for further research into the field

\section{Conflict of interest}

The authors declare no conflict of interest. The authors alone are responsible for the content and writing of the paper.

\section{References}

1. Weerheijm KL, Duggal M, Mejare I, Papagiannoulis L, Koch G, Martens LC, et al. Judgement criteria for molar incisor hypomineralisation (MIH) in epidemiologic studies: a summary of the European meeting on MIH held in Athens, 2003. Eur J Paediatr Dent. 2003; 4: 110-113. 
2. William V, Messer LB, Burrow MF. Molar incisor hypomineralization: review and recommendations for clinical management. Pediatr Dent. 2006; 28: 224-232.

3. Chay PL, Manton DJ, Palamara JEA. The effect of resin infiltration and oxidative pre-treatment on microshear bond strength of resin composite to hypomineralised enamel. Int J Paediatr Dent. 2014; 24: 1-16.

4. Paris S, Meyer-Lueckel H, Kielbassa AM. Resin infiltration of natural caries lesions. J Dent Res. 2007; 86: 662-666.

5. Crombie FA, Manton DJ, Palamara JE, Zalizniak I, Cochrane NJ, Reynolds EC. Characterisation of developmentally hypomineralised human enamel. J Dent. 2013; 41: 611-618.

6. Silverstone LM. Structure of carious enamel, including the early lesion. Oral Sci Rev. 1973; 3: 100-160.

7. Bergman G, Lind PO. A quantitative microradiographic study of incipient enamel caries. J Dent Res. 1966; 45: 1477-1484.

8. Ghanim A, Morgan M, Mariño R, Bailey D, Manton D. Molar-incisor hypomineralisation: prevalence and defect characteristics in Iraqi children. Int J Paediatr Dent. 2011; 21: 413-421.

9. Xie ZH, Mahoney EK, Kilpatrick NM, Swain MV, Hoffman M. On the structure-property relationship of sound and hypomineralized enamel. Acta Biomater. 2007; 3: 865-872.

10. Xie Z, Kilpatrick NM, Swain MV, Munroe PR, Hoffman M. Transmission electron microscope characterisation of molar-incisor-hypomineralisation. $\mathrm{J}$ Mater Sci Mater Med. 2008; 19: 3187-3192.

11. Suckling GW, Nelson DG, Patel MJ. Macroscopic and scanning electron microscopic appearance and hardness values of developmental defects in human permanent tooth enamel. Adv Dent Res. 1989; 3: 219-33.

12. Mahoney E, Ismail FS, Kilpatrick N, Swain M. Mechanical properties across hypomineralized/hypoplastic enamel of first permanent molar teeth. Eur J Oral Sci. 2004; 112: 497-502.

13. Mahoney EK, Rohanizadeh R, Ismail FS, Kilpatrick NM, Swain MV. Mechanical properties and microstructure of hypomineralised enamel of permanent teeth. Biomaterials. 2004; 25: 5091-5100. 
14. Farah RA, Drummond BK, Swain MV, Williams S. Relationship between laser fluorescence and enamel hypomineralisation. J Dent. 2008; 36: 915-921.

15. Jalevik B, Noren JG. Enamel hypomineralization of permanent first molars: a morphological study and survey of possible aetiological factors. Int J Paediatr Dent. 2000; 10: 278-289.

16. Jalevik B. Enamel hypomineralization in permanent first molars. A clinical, histo-morphological and biochemical study. Swed Dent J Suppl. 2001; 149: 1-

86.

17. Farah RA, Swain MV, Drummond BK, Cook R, Atieh M. Mineral density of hypomineralised enamel. J Dent. 2010; 38: 50-58.

18. Crombie FA, Manton DJ, Palamara J, Kilpatrick NM, Reynolds EC. Enamel Hardness of Molar Hypomineralisation Affected Teeth. Caries Res. 2009; 43: $179-244$.

19. Mangum JE, Crombie FA, Kilpatrick N, Manton DJ, Hubbard MJ. Surface integrity governs the proteome of hypomineralized enamel. J Dent Res. 2010; 89: 1160-1165.

20. Kim S, Kim EY, Jeong TS, Kim JW. The evaluation of resin infiltration for masking labial enamel white spot lesions. Int J Paediatr Dent. 2011; 21: 241248.

21. Crombie F, Manton D, Palamara J, Reynolds E. Resin infiltration of developmentally hypomineralised enamel. Int J Paediatr Dent. 2014; 24: 51-55

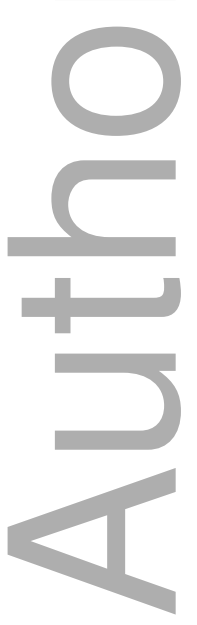




\section{Figure Legends}

Figure 1: Groups and number of specimens allocated for the etch time analysis.

Figure 2: Preparation of specimens for the etch time and surface layer study ${ }^{\text {a-e }}$.

${ }^{\text {a }}$ Hypomineralised lesion scored and classified as mildly or moderately affected

${ }^{\mathrm{b}}$ Roots of the first permanent molar sectioned

${ }^{\mathrm{c}}$ Varnish applied to block out all areas adjacent to the selected test regions on hypomineralised and control enamel. Specimen etched for required time

${ }^{\mathrm{d}}$ Specimen embedded in resin

${ }^{\mathrm{e}}$ Specimen sectioned into 0.7 - $1 \mathrm{~mm}$ slices

Figure 3: Groups and number of specimens allocated for resin infiltration study.

Figure 4: Preparation of specimens for the resin infiltration study ${ }^{\mathrm{a}-\mathrm{e}}$.

a. Hypomineralised lesion categorised

b. Roots sectioned and the hypomineralised lesion sectioned into test and control halves

c. Varnish applied to cut surfaces of both halves. The test half (hypomineralised lesion and the visually sound enamel apical to the lesion) was infiltrated with Icon $^{\circledR}$

d. Specimen embedded in PMMA resin

e. Specimen sectioned to produce two $2-3 \mathrm{~mm}$ slices and the cut surface to be analysed was lapped till the varnish was removed, then polished

Figure 5: Hardness values from occlusal cusp tip to cervical divided into zones. Dots on sample represent approximate location of Knoop hardness readings.

Figure 6: Polarised light microscopy images under water imbibition at 5x magnification of etched samples ${ }^{\mathrm{a}-\mathrm{c}}$.

${ }^{\mathrm{a}}$ Sample etched for $90 \mathrm{sec}$

${ }^{\mathrm{b}}$ Sample etched for $120 \mathrm{sec}$

${ }^{\mathrm{c}}$ Sample etched for 120sec repeated twice (240sec)

1 = Surface layer; 2 = Varnish; $3=$ Occlusal enamel etch erosion step; 4 = Hypomineralised enamel; 5

$=$ Cervical enamel etch erosion step

Figure 7: Variation in enamel hypomineralisation shape and location ${ }^{\mathrm{a}}$.

${ }^{\text {a }}$ Samples taken from consecutive sections of the same specimen

Figure 8: Mean Knoop hardness from occlusal cusp tip to cervical of all control samples with visually sound enamel present above the hypomineralised enamel lesion.

Figure 9: Mean Knoop hardness from occlusal cusp tip to cervical of all control samples with enamel hypomineralization extending to the cusp tip. 
Figure 10: Representative images of infiltrated specimens.

VIA = Visibly Infiltrated Area

Figure 11: Mean Knoop hardness of all test samples from occlusal cusp tip to cervical comparing samples that appeared to have infiltrated vs. not infiltrated.

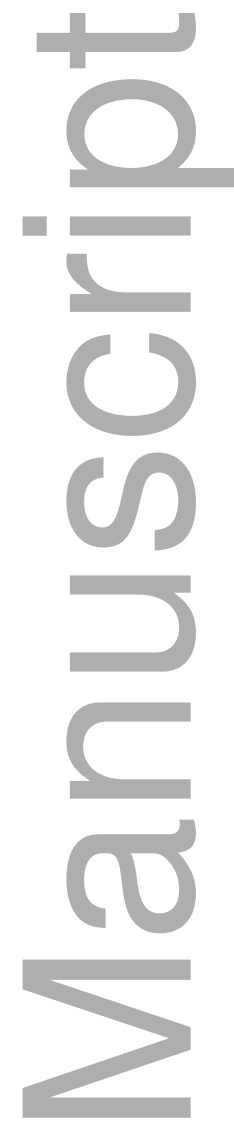

Table 1: Modified scoring system for MIH affected teeth ${ }^{8}$.

\begin{tabular}{|c|c|}
\hline Criteria for scoring MIH & $\begin{array}{c}\text { Criteria for evaluating extent of MIH } \\
\text { lesions }\end{array}$ \\
\hline $\begin{aligned} 0= & \text { Enamel defect free } \\
1= & \text { White or creamy demarcated opacities; } \\
& \text { no post- eruptive breakdown (PEB) } \\
& \text { (MILD) } \\
1 \mathrm{a}= & \text { White or creamy demarcated opacities; } \\
& \text { with PEB (SEVERE) } \\
2= & \text { Yellow or brown demarcated opacities; } \\
& \text { no PEB (MODERATE) } \\
2 \mathrm{a}= & \text { Yellow or brown demarcated opacities; } \\
& \text { with PEB (SEVERE) }\end{aligned}$ & $\begin{array}{l}1 \text { = Less than one third of tooth surface } \\
2 \text { = At least one third but less than two thirds } \\
\text { of tooth surface } \\
3 \text { = At least two thirds of tooth surface }\end{array}$ \\
\hline
\end{tabular}

This article is protected by copyright. All rights reserved 
$3=$ Atypical restoration

4 = Diffuse opacities (Not MIH)

5 = Hypoplasia (Not MIH)

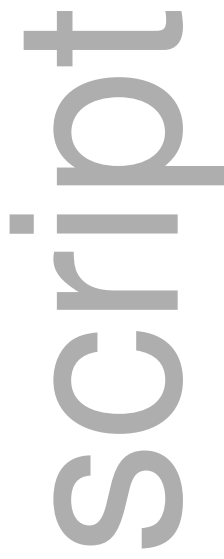

Table 2: Mean surface layer thickness and enamel loss by hydrochloric acid erosion as a percentage of surface layer thickness.

\begin{tabular}{|c|c|c|c|c|}
\hline $\begin{array}{c}\text { No. of } \\
\text { samples } \\
(\mathbf{n})\end{array}$ & MIH & $\begin{array}{c}\text { Etch } \\
\text { time } \\
(\mathbf{s e c})\end{array}$ & $\begin{array}{c}\text { Surface layer } \\
\text { thickness }(\boldsymbol{\mu m}) \\
(\mathbf{S D})\end{array}$ & $\begin{array}{c}\text { Enamel eroded as } \\
\text { a percentage of } \\
\text { surface layer } \\
\text { thickness (\%) } \\
(\mathbf{S D})\end{array}$ \\
\hline $12 / 14$ & Mild & 90 & $63.56(26.68)$ & $107.16(62.51)$ \\
\hline 9 & Moderate & 90 & $62.69(41.21)$ & $64.47(38.43)$ \\
\hline 8 & Mild & 120 & $60.57(33.30)$ & $123.58(69.02)$ \\
\hline $7 / 9$ & Moderate & 120 & $71.35(36.58)$ & $107.65(47.50)$ \\
\hline $7 / 8$ & Mild & $120 \times 2$ & $33.94(10.84)$ & $367.03(134.61)$ \\
\hline 9 & Moderate & $120 \times 2$ & $54.56(24.59)$ & $200.00(134.51)$ \\
\hline Total $=$ & & & Mean = 57.78 & \\
\hline $\mathbf{5 2 / 5 7}$ & & & $(28.87)$ & \\
\hline
\end{tabular}


Table 3: Difference in surface layer thickness within samples from the same specimen.

\begin{tabular}{|c|c|c|c|}
\hline Specimen No. & $\begin{array}{l}\text { No. of samples } \\
\text { from specimen } \\
(\text { Total = 57) }\end{array}$ & $\begin{array}{c}\text { Surface layer } \\
\text { thickness range }^{1} \\
(\mu \mathrm{m})\end{array}$ & Difference $(\mu \mathrm{m})$ \\
\hline & 4 & $18.49-47.86$ & 29.37 \\
\hline 2 & 4 & $19.53-95.96$ & 76.43 \\
\hline & 3 & $44.48-145.42$ & 100.94 \\
\hline 4 & 1 & 50.91 & N/A \\
\hline 5 & 3 & $54.29-128.80$ & 74.51 \\
\hline ( & 5 & $37.19-118.16$ & 80.97 \\
\hline 7 & 1 & 44.62 & N/A \\
\hline 8 & 1 & Not present & N/A \\
\hline 9 & 9 & $21.44-63.47$ & 42.03 \\
\hline 10 & 2 & $22.19-36.86$ & 14.67 \\
\hline 11 & 4 & $35.66-59.13$ & 23.47 \\
\hline 12 & 3 & $47.05-49.95$ & 2.90 \\
\hline 13 & 8 & $31.00-113.92$ & 82.92 \\
\hline
\end{tabular}




\begin{tabular}{|c|c|c|c|}
\hline 14 & 3 & $34.23-49.75$ & 15.52 \\
\hline 15 & 3 & $54.46-57.89$ & 3.43 \\
\hline 16 & 1 & 45.56 & N/A \\
\hline 17 & 1 & 140.78 & N/A \\
\hline 18 & 1 & 43.16 & N/A \\
\hline
\end{tabular}

${ }^{1}$ Range: the highest and lowest values of the samples in each group

Table 4: Six consecutive Knoop hardness (KHN) values of control samples in the most severely affected region within hypomineralised enamel.

\begin{tabular}{|c|c|c|c|c|c|c|c|}
\hline $\begin{array}{c}\text { Tooth } \\
\text { Number }\end{array}$ & Severity & $\begin{array}{l}\text { Site } 1 \\
(\mathrm{KHN})\end{array}$ & $\begin{array}{l}\text { Site } 2 \\
(\mathrm{KHN})\end{array}$ & $\begin{array}{c}\text { Site } 3 \\
(\mathrm{KHN})\end{array}$ & $\begin{array}{l}\text { Site } 4 \\
(\mathrm{KHN})\end{array}$ & $\begin{array}{l}\text { Site } 5 \\
(\mathrm{KHN})\end{array}$ & $\begin{array}{r}\text { Site } 6 \\
(\mathrm{KHN})\end{array}$ \\
\hline 1 & Moderate & 22.2 & 7.8 & 2.2 & 2.2 & 1.6 & 7 \\
\hline 2 & Moderate & 50.4 & 75.4 & 30.4 & 30.4 & 27.9 & 54.5 \\
\hline 3 & Mild & 38.6 & 27.1 & 34.1 & 63.5 & 53.8 & 46.6 \\
\hline 4 & Mild & 98.2 & 68.8 & 71 & 53.6 & 66.5 & 77.6 \\
\hline 5 & Mild & 71.2 & 99.4 & 176.7 & 148.2 & 134.8 & 177.2 \\
\hline 6 & Moderate & 12 & 9.7 & 14.5 & 9 & 11.4 & 27.9 \\
\hline 7 & Mild & 83.8 & 61.7 & 57.9 & 62.5 & 55.4 & 70.3 \\
\hline 8 & Moderate & 30.5 & 24.1 & 29 & 27.4 & 27 & 26.4 \\
\hline 9 & Mild & 50.6 & 68.7 & 53.5 & 52.5 & 37.9 & 64.9 \\
\hline 10 & Mild & 15.6 & 12.6 & 17.4 & 21.7 & 53.3 & 67.9 \\
\hline 11 & Mild & 55.7 & 34.7 & 35.3 & 27.3 & 22.5 & 15.9 \\
\hline 12 & Mild & 73.9 & 48.8 & 40.6 & 52.9 & 37.2 & 37.9 \\
\hline 13 & Mild & 135 & 77.8 & 59.6 & 91.9 & 172.1 & 271.2 \\
\hline 14 & Moderate & 38.4 & 41 & 31.6 & 27.5 & 8.8 & 27.9 \\
\hline 15 & Moderate & 8.9 & 7.8 & 6.7 & 9.8 & 12.6 & 13.2 \\
\hline 16 & Moderate & 88.5 & 82.4 & 28.1 & 10.4 & 38.2 & 57.5 \\
\hline 17 & Moderate & 100.5 & 133.9 & 186.4 & 89.5 & 123.9 & 113.3 \\
\hline 18 & Mild & 184.9 & 112.7 & 134.3 & 145.1 & 188.6 & 220.7 \\
\hline 19 & Moderate & 16.6 & 66.4 & 72.3 & 55.3 & 71.3 & 75.4 \\
\hline 20 & Moderate & 19.9 & 20.8 & 30.7 & 27.1 & 28.3 & 37 \\
\hline 21 & Moderate & 48.7 & 69 & 62.2 & 71 & 99.2 & 107.1 \\
\hline 23 & Mild & 196.8 & 110.4 & 75.9 & 96.7 & 85.5 & 94.9 \\
\hline
\end{tabular}


ตำแท 1

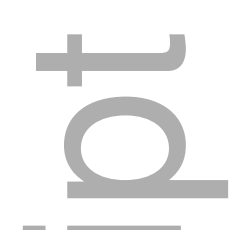

$\square$
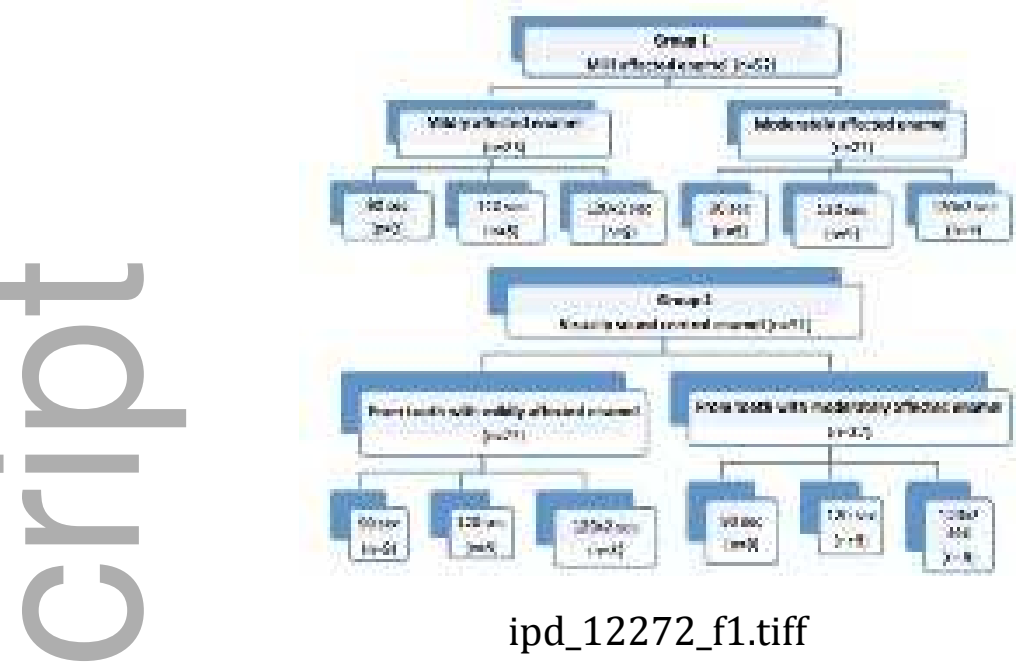

ipd_12272_f1.tiff
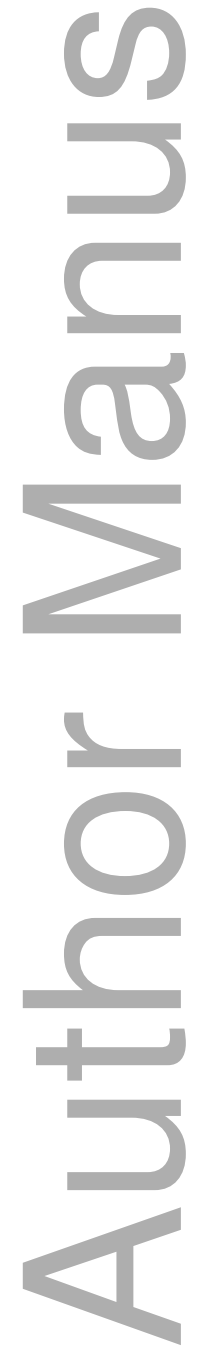

This article is protected by copyright. All rights reserved 


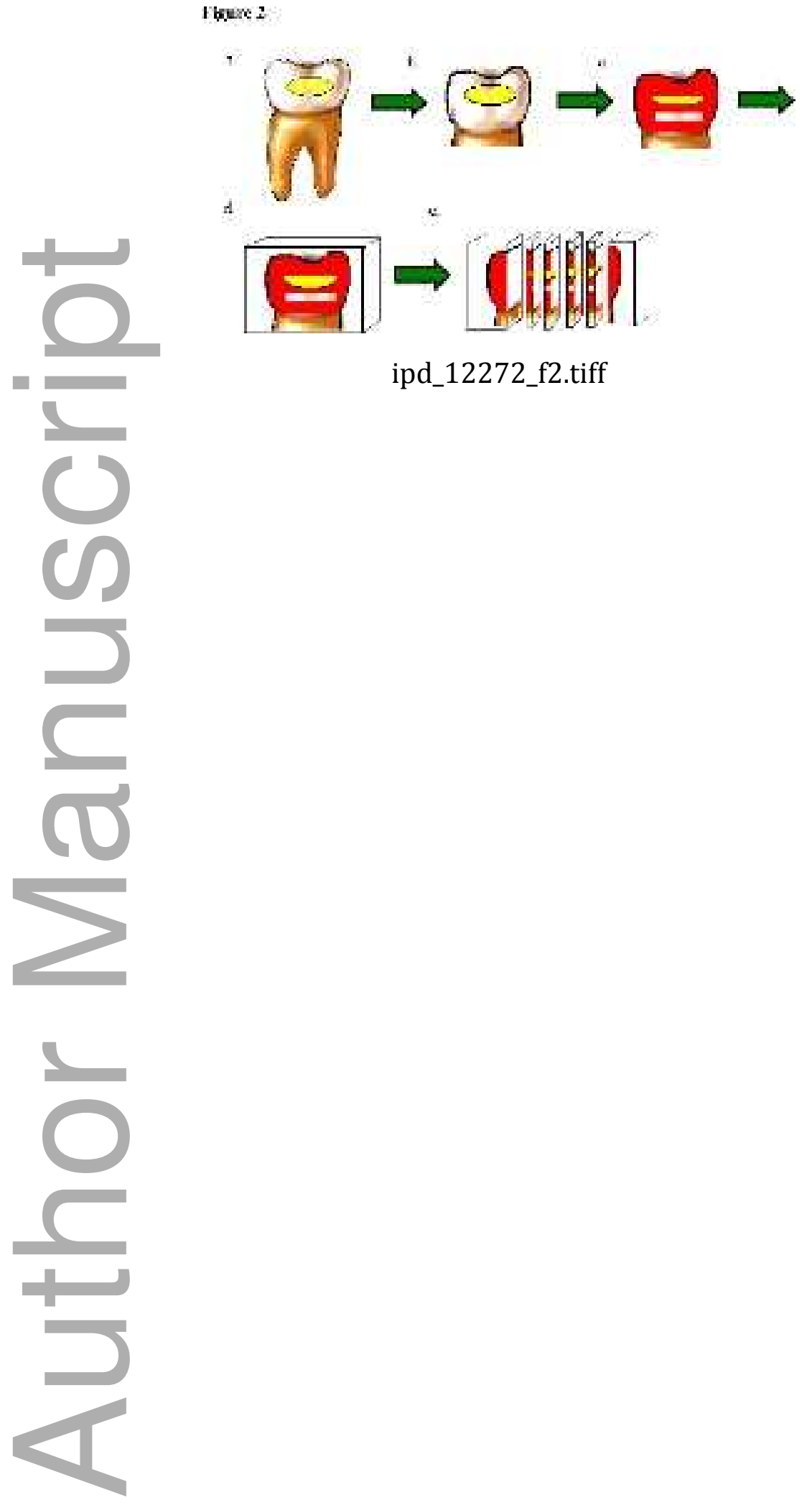

This article is protected by copyright. All rights reserved 


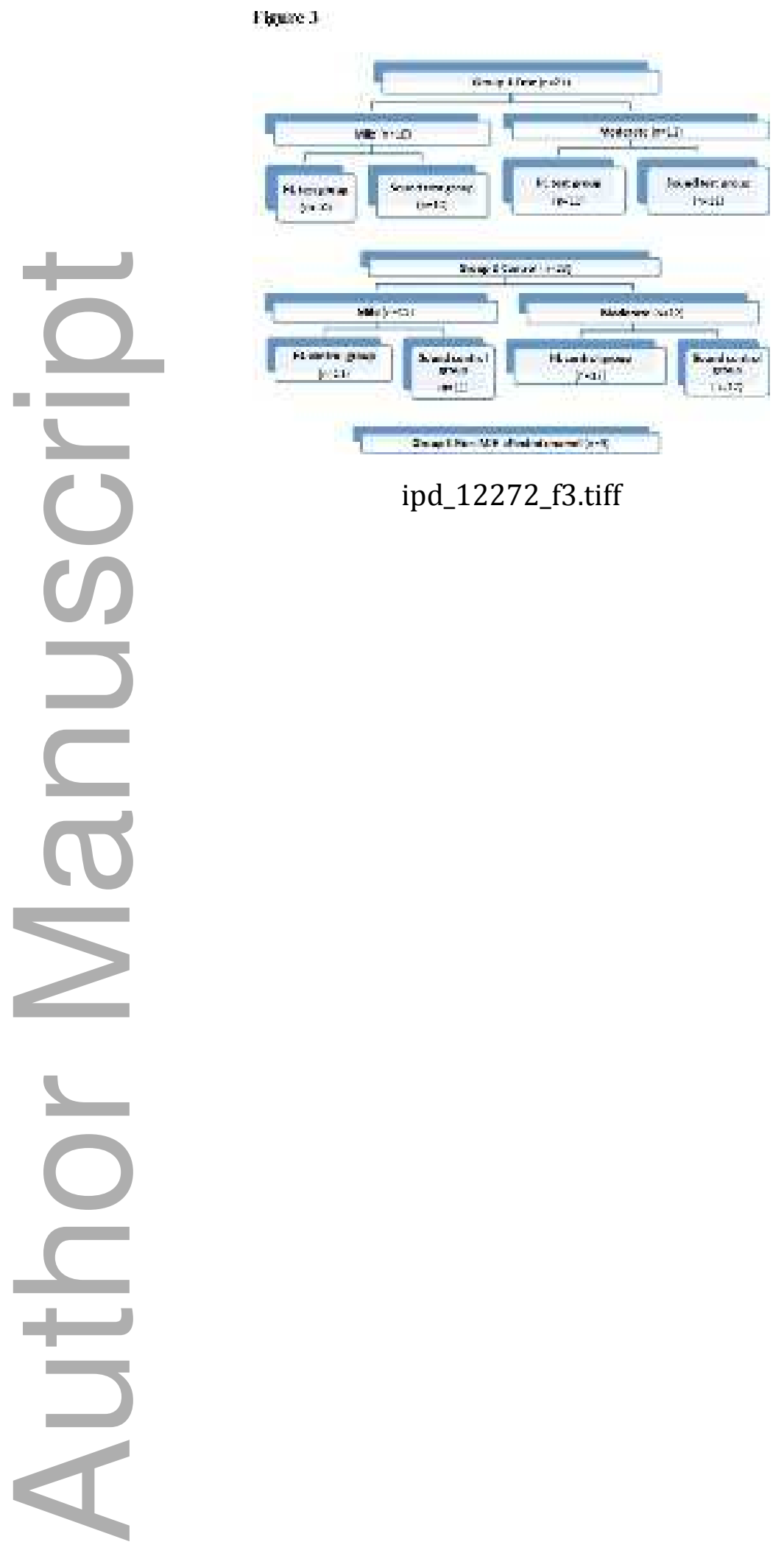

This article is protected by copyright. All rights reserved 


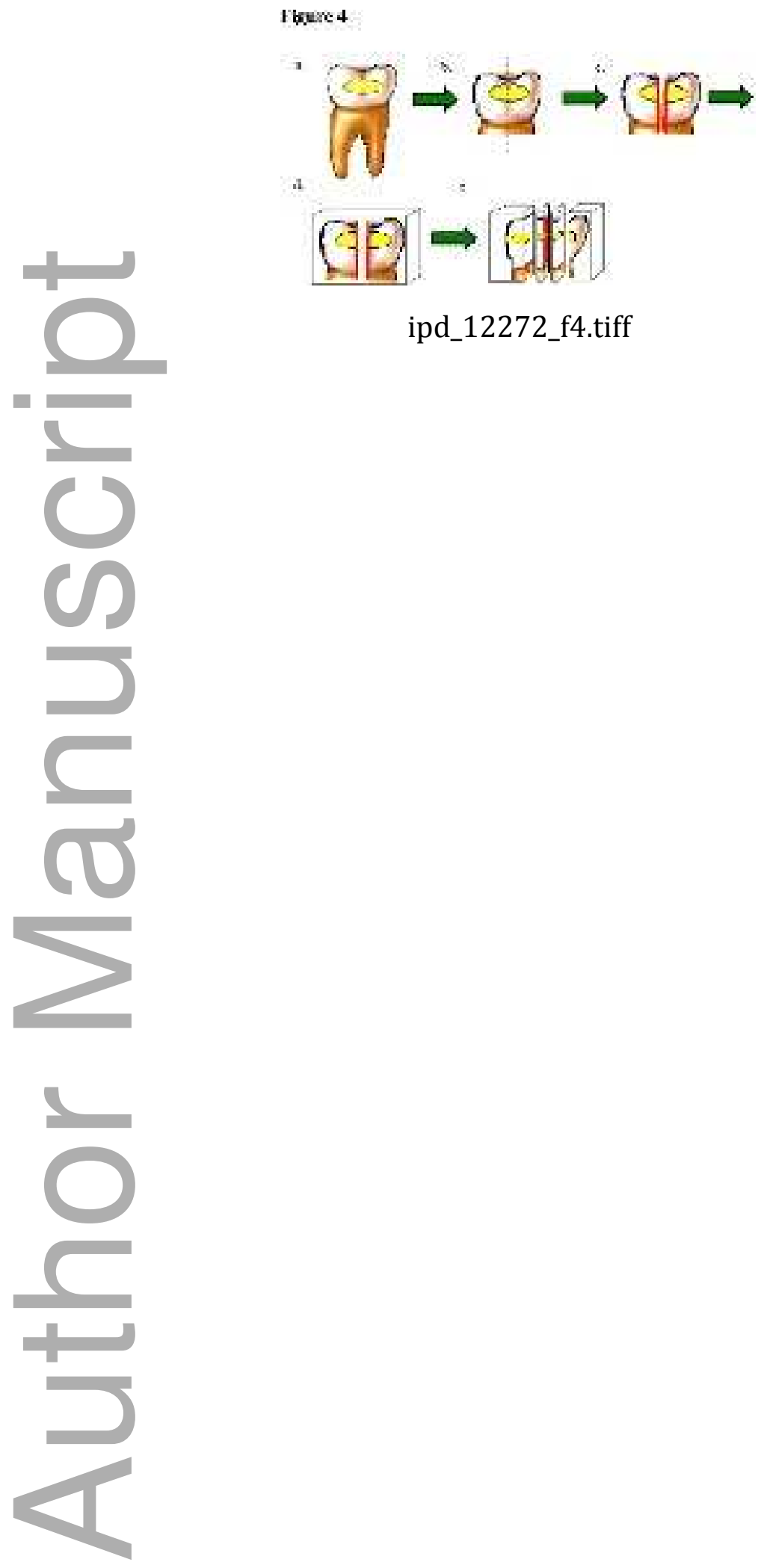

This article is protected by copyright. All rights reserved 


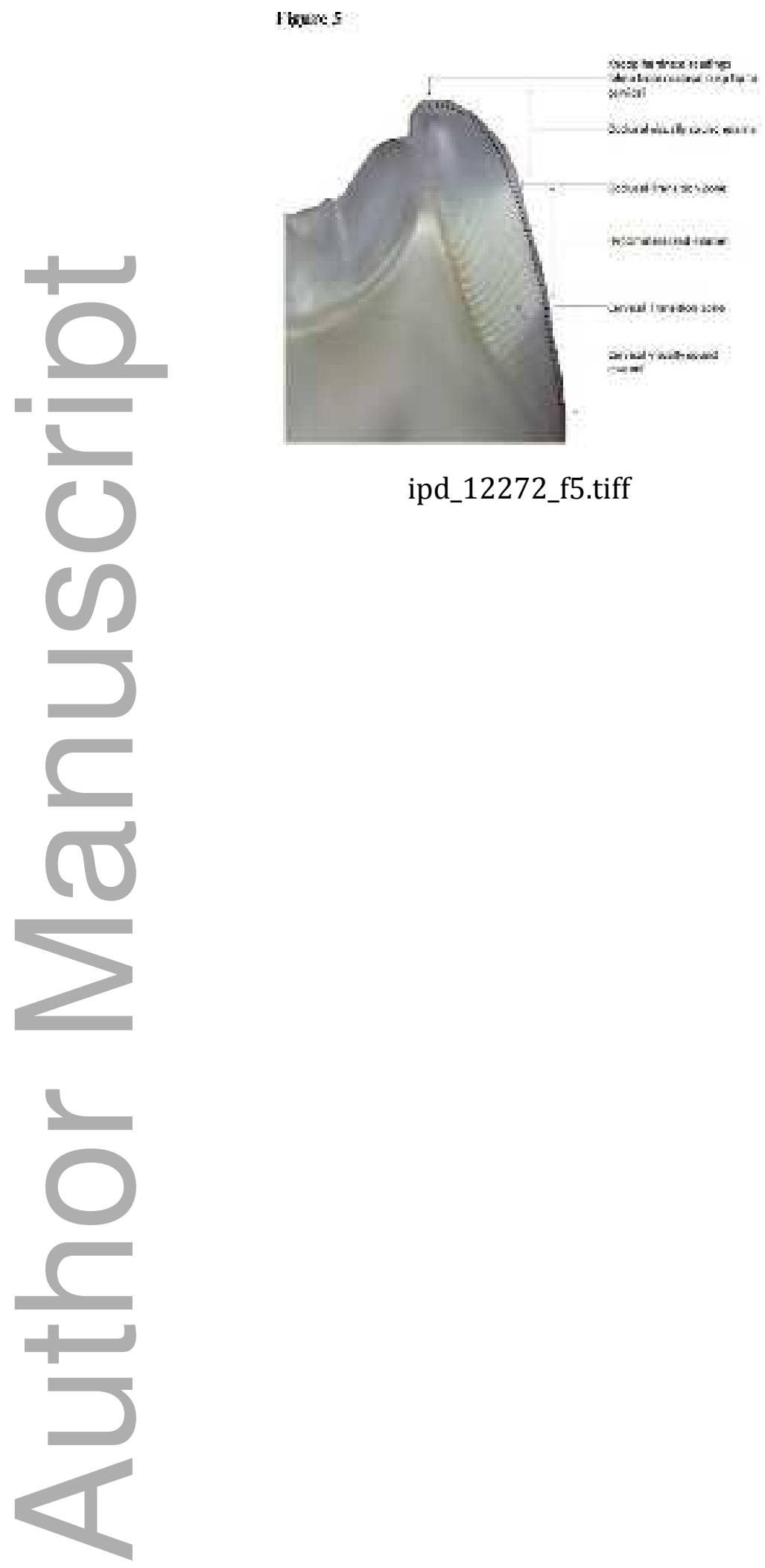

This article is protected by copyright. All rights reserved 


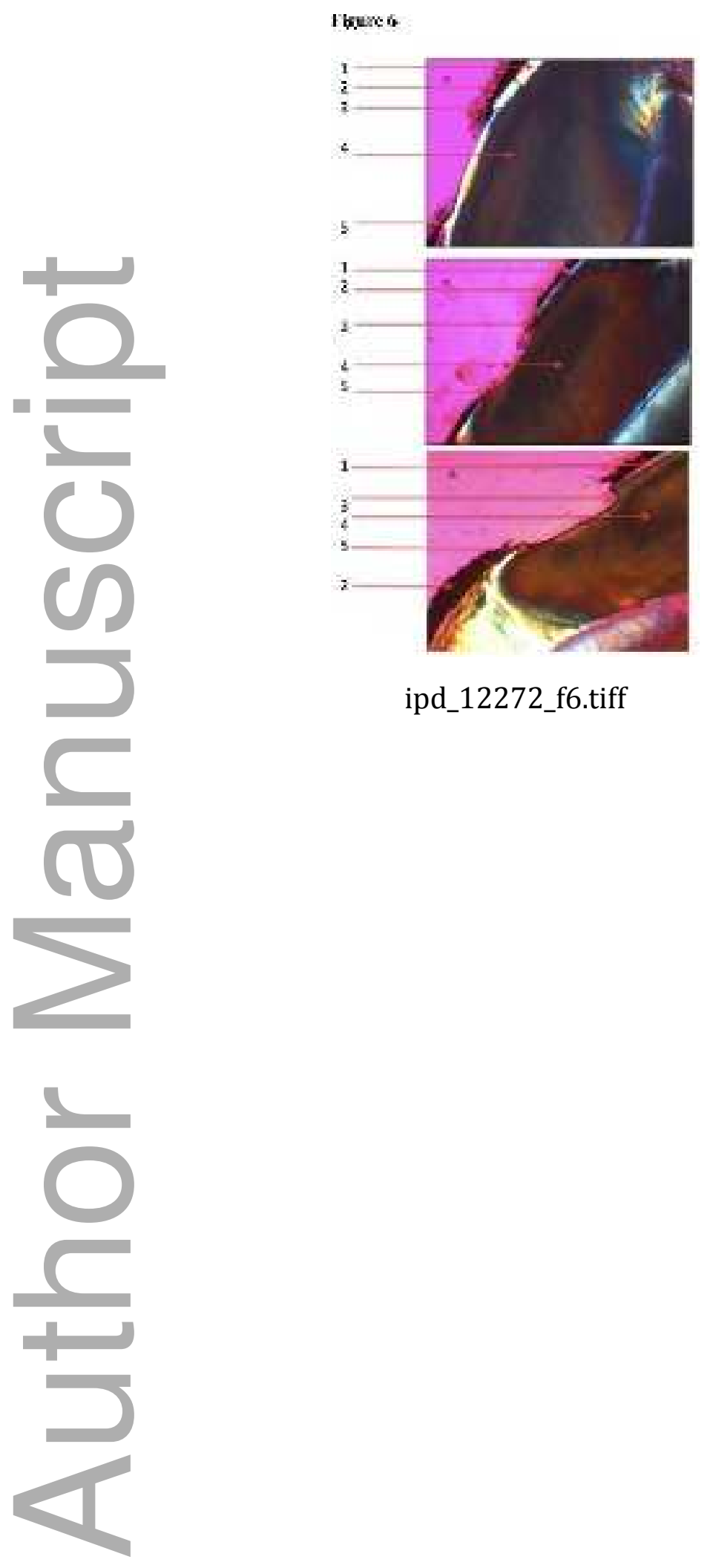

This article is protected by copyright. All rights reserved 


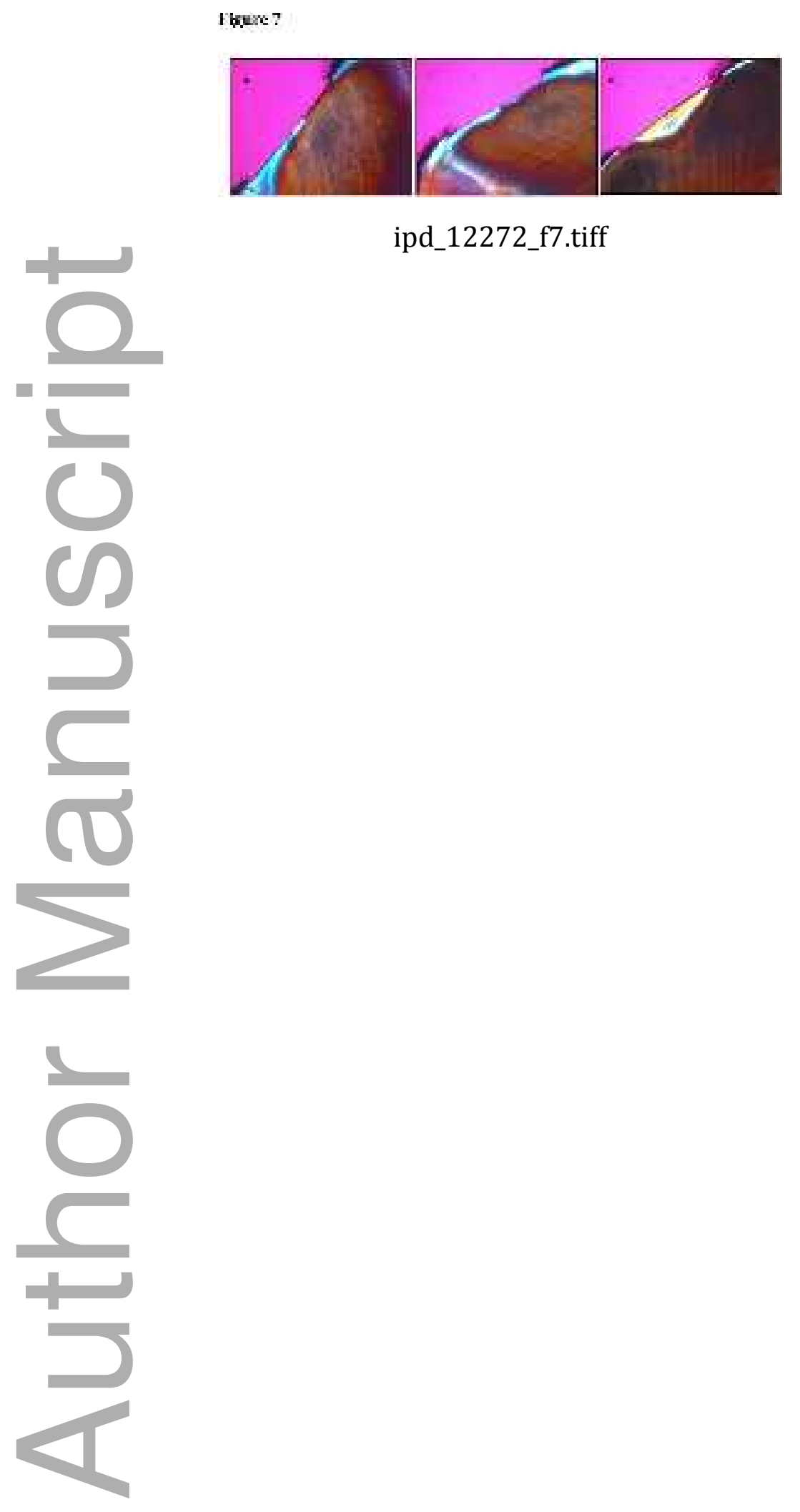

This article is protected by copyright. All rights reserved 


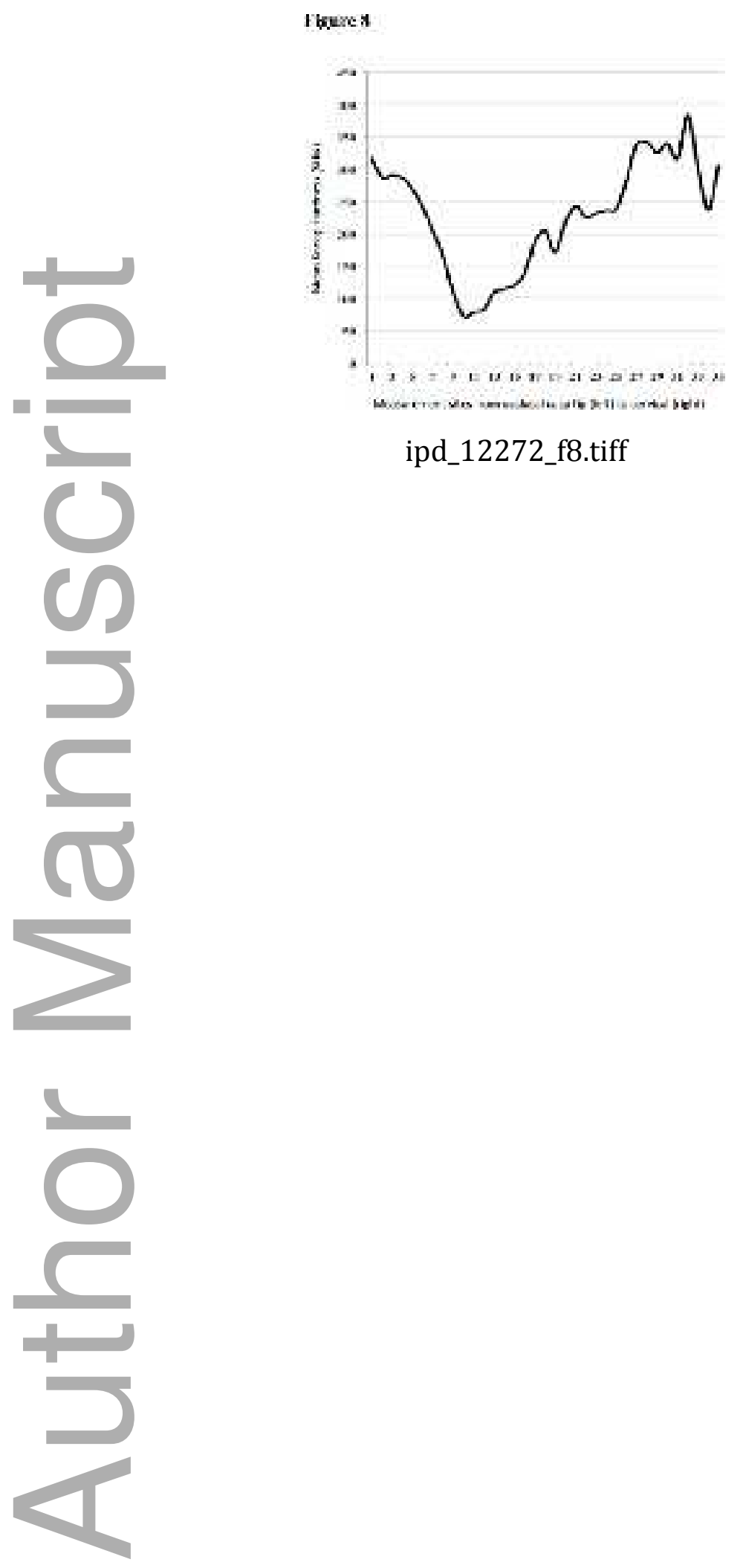

This article is protected by copyright. All rights reserved 


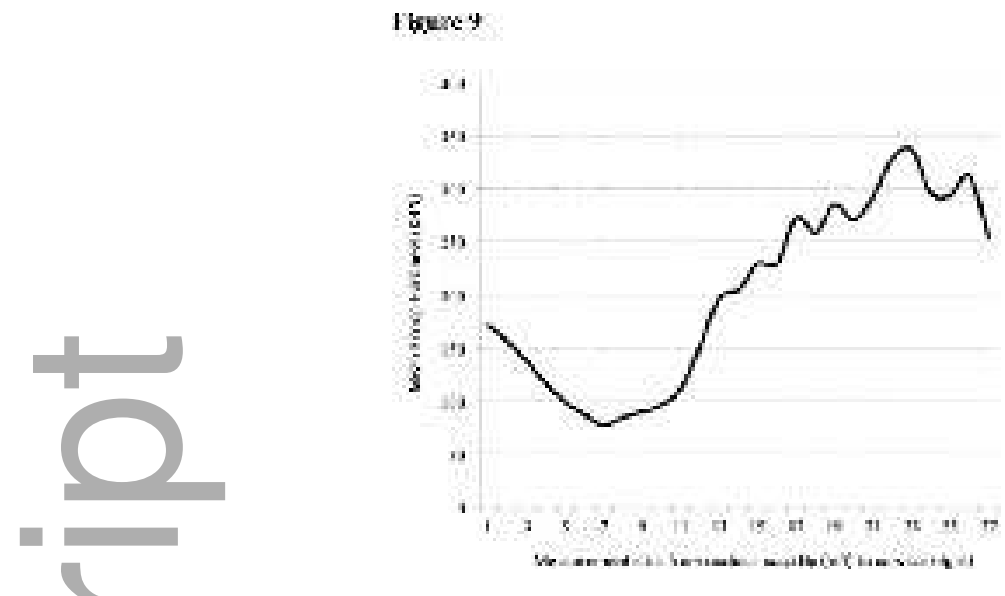

ipd_12272_f9.tiff

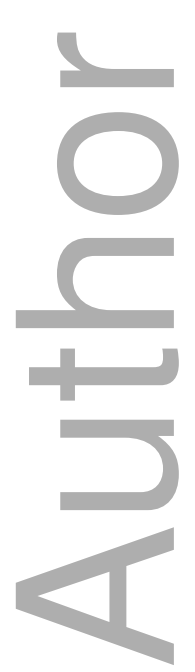

This article is protected by copyright. All rights reserved 


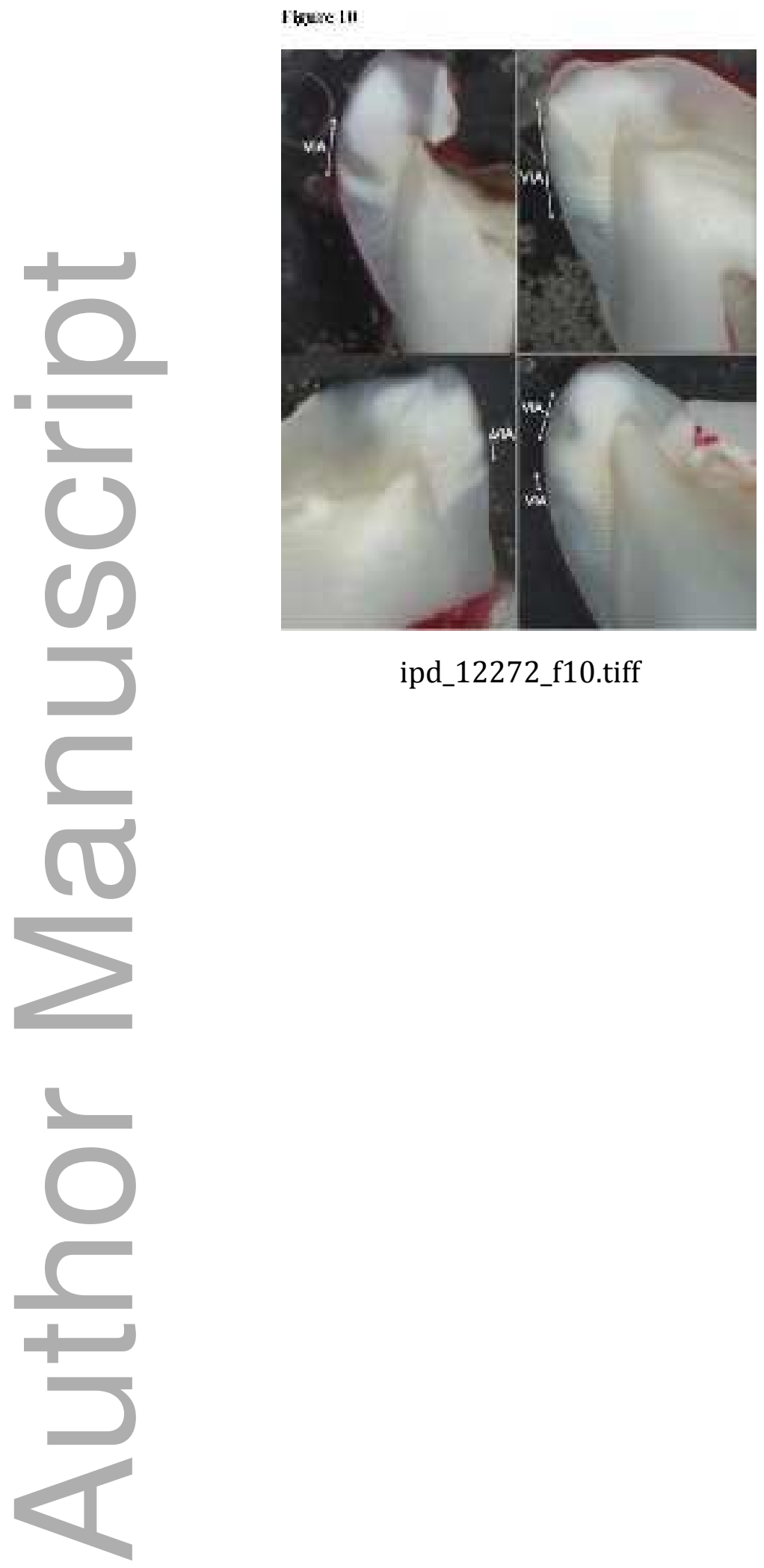

This article is protected by copyright. All rights reserved 


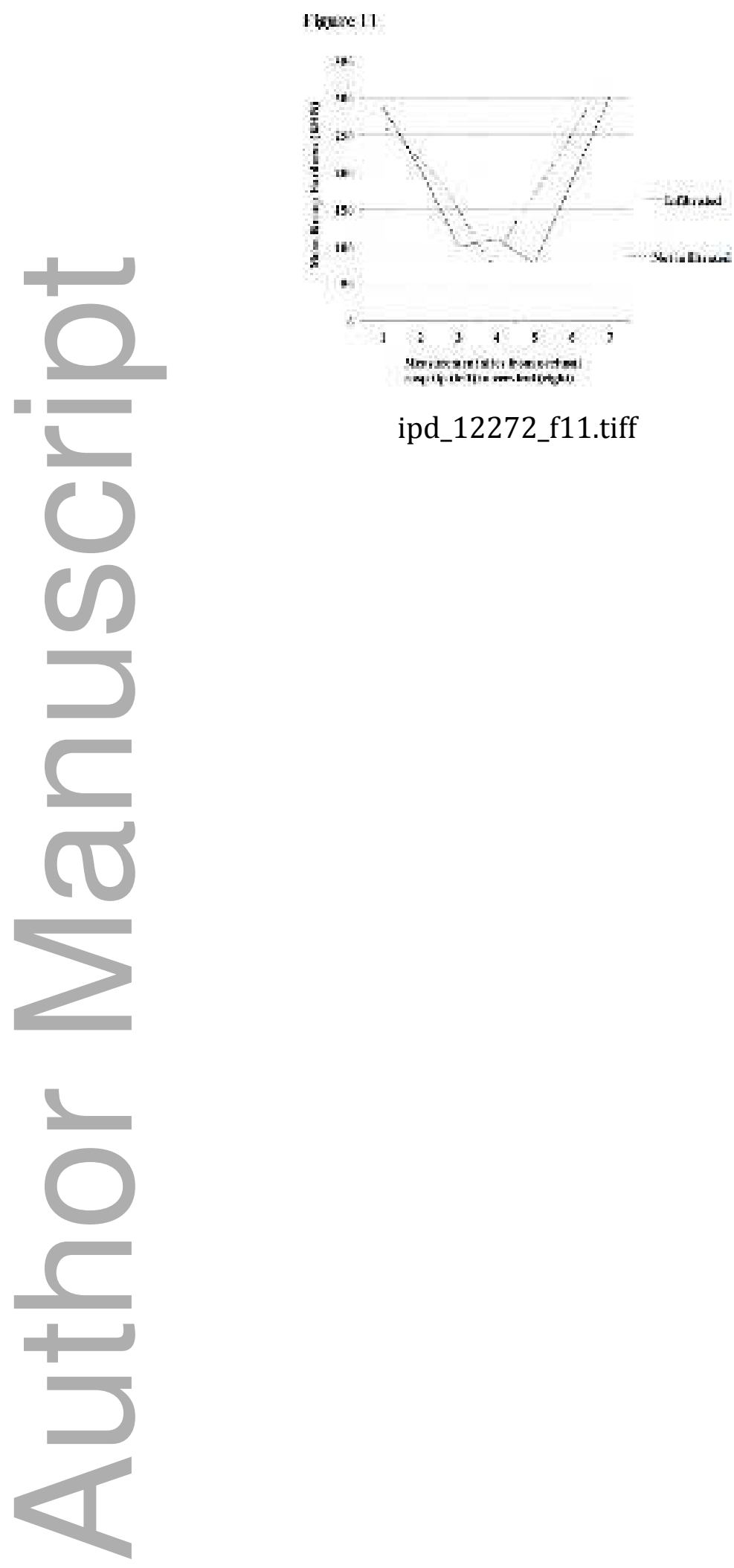

This article is protected by copyright. All rights reserved 


\section{University Library}

\section{- M M N E R VA A gateway to Melbourne's research publications}

Minerva Access is the Institutional Repository of The University of Melbourne

Author/s:

Kumar, H;Palamara, JEA;Burrow, MF;Manton, DJ

Title:

An investigation into the effect of a resin infiltrant on the micromechanical properties of hypomineralised enamel

Date:

2017-09-01

\section{Citation:}

Kumar, H., Palamara, J. E. A., Burrow, M. F. \& Manton, D. J. (2017). An investigation into the effect of a resin infiltrant on the micromechanical properties of hypomineralised enamel. INTERNATIONAL JOURNAL OF PAEDIATRIC DENTISTRY, 27 (5), pp.399-411. https:// doi.org/10.1111/ipd. 12272.

Persistent Link:

http://hdl.handle.net/11343/292113 